\title{
Study on the Living Environment of Lanzhou City
}

\author{
Hongfei Li, Benteng Liu \\ School of Design and Art, Lanzhou University of Technology, Lanzhou, 730050, China \\ Ihf117@126.com
}

\begin{abstract}
Keywords: Living Environment; Sustainable Development ;Lanzhou
Abstract. The living environment is the base of the survival and development of human, its sustainable development is directly related to the extent of human life and it is one of most important content that measure the progress of human society and culture development. With the rapid development of economy and people's life quality improved steadily, more and more people pay attention to the seriousness of the living environment. Based on the research of the sustainable development of the city living environment, combined with the present situation of Lanzhou city residential environment, offer the countermeasures and suggestions which can promote the sustainable development of human settlements in Lanzhou City, and from the point of view that city environment and future sustainable development, and adhere to the "people-oriented" principle, to provide a reference to the relevant departments of the government.
\end{abstract}

\section{Background}

People's living standard have significantly improved by the rapid development of the economy of China. People paying attention to the issues of living environment and sustainable development when they pursuit of quality of life in the process of continuous improvement. The pursuit of high quality of life makes people want to enjoy a quality living environment. The problem of survival environment of city become the study that majority of scholars pay close attention to and further research very naturally because of large people living there. It is the only way of the construction of modern city that building a beautiful living environment and the achieve the sustainable development of human settlements in the city by the practice.

Lanzhou city is located in the northwest semi-arid climate zone, is located in a narrow valley in Valley City in Northwest China, belongs to the typical valley basin terrain, the special social and economic conditions and restricted to a great extent the living environment of the city development, it is one of China's city living environment and sustainable development in the more prominent contradiction city. Study on the sustainable development of human settlements in Lanzhou city is not only can guide the optimization of construction of Lanzhou city residential environment but also has certain reference function to other city sustainable development in northwest China habitat environment.

\section{The concept of the living environment}

The living environment can not be simply understood as the human living environment, it has rich connotation and value of study. Since twentieth Century 50 years, Sadiyasi Greek scholars put forward the concept of "the science of human settlements", the living environment has become the focus of architecture, planning, geography, environmental science and so on. The living environment, in other words is the place that human beings to live in a compact community and the spatial surface that closely related to human survival activities, It is the base that human beings living in the nature, and the main place that human use and transform the nature.

From the beginning of 80's in the last century, Mr. Wu Liangyong began working on "study on the science of human settlements" and then he put forward the basic frame of the Thescience of Human Settlements. This framework considers various scales, at all levels of the human settlements environment and covering the country to the city, it is not only the problems of architecture or city. The science of living environment is a new discipline, it is developed based on science of human habitation, environment science. It is a comprehensive discipline, and the synthesis of architecture, city planning and landscape architecture, it is centered by human settlements activities. In this wide place, people can 
do many kinds of rich and colorful activities such as labor, life, living, rest, recreation, social networking and so on.

The living environment is the living activities of city residents and the relation of all the background of subject and object to each other. It includes the physical space of residents living and activities and various factors in the population, resources, environment, social and economic development. The science of living environment is not a single level academic scope, the characteristics of it is use the main building and the surrounding environment comfortable to discuss the problem of human living because of the origin of the study is the artificial environment of Architectural Science. At the same time, it showing a colorful discipline charm for the discipline structure of living environment science. The living environment can not clear its concept only by simply expansion of human settlements or narrow the regional system. It is based on the architecture science and related to the natural science and the humanities environment, ecology, geography, society, economy and other aspects of city planning.

\section{Survey of Lanzhou city}

Lanzhou city is located in the Western Loess Plateau, which belongs to the north temperate continental monsoon climate with weak drought, drought little rain, dry climate, loess denudation, low vegetation coverage, soil erosion is serious, the ecological environment is very fragile, the two seasons is easily affected by dust storms and dust weather and the natural dust is serious. Lanzhou city is confrontation between two mountains from north south and become a long narrow strip City, and it has a high static wind rate. The special topography and meteorological conditions is not conducive to the dilution and diffusion of pollutants in the air of city. In the area of high mountains and steep slopes, ravines, complex geological conditions, Lanzhou is one of the Chinese landslide, debris flow and even the most serious area in the world, and it is the few capital city of our country that troubled by the geological effects of natural disasters. Due to the natural ecological environment is very fragile and economic development is always expense of the environment for long term, the natural ecological environment and sustainable is very bad in Lanzhou city.

On the other hand the city land price is very high because of the city development land is obviously insufficient for its valley and the population and industry agglomeration rapidly intensified the conflict between various types of construction land. The construction of city residential environment quality is effected by the per capita living area, residential and industrial enterprises of mixed distribution, public green space ratio decreased and public green space ratio decreased. Although in recent years the living environment of Lanzhou valley city development is promoted by the bankroll that putted into the living environment with the development of economy, but it is cannot effectively solve the problem of city construction land and improve the living environment and infrastructure because of the weak economic foundation and backward economic strength of Lanzhou, especially living environment sustainable decreased gradually by environmental remediation which leading to the city is crowded and the green land is very rare. Therefore unfavorable factors of the typical regional conditions determine the long-term and necessity of city human settlements environmental construction.

\section{The optimization strategy of living environment of Lanzhou city}

The overall level of the whole living environment system of Lanzhou is the worst in the same city because of its living environment is at a relatively low level of development. The poor ecological environmental quality is the main factors restricting the Lanzhou City Human Settlements Construction benign sustainable development. Therefore, the main direction of future development strategy of Lanzhou City is to implement the protection of the natural environment and ecological environment construction, and then to speed up the basic construction of city, improve the image of the city as a supplement and promote the development of economy and society in the further.

\section{Adhere to the "people-oriented", promote the concept of sustainable development.}

In the overall planning of the city we should reflect the people-oriented principle. The infrastructure, public buildings, planning, commercial public buildings and residential area planning should be closely around the "people" as the theme, All the planning principles and development methods are based on "people" as the center, human health and comfort, convenience and safety is the first consideration should be given. In the process of old city transformation and new construction, the first consideration 
is to provide convenient traffic conditions for the public to travel, and in the planning approval process, we must always emphasize the density of road network and improve the public facilities and provide more leisure and entertainment to the public. At the same time, the city should promote the sustainable development of living environment and the concept, promote the fine style of hard work and plain living, resolutely resist the bad consumption patterns and ideas, improve the public collective rational consumption and the consciousness of environmental protection, and oppose money worship, "GDP worship" and "pure economic rationalism". We should guide people to understand the importance of the environment, promote the concept of sustainable development and appeal $f$ all the people involved in the sustainable development of the construction of living environment.

\section{The development of recycling economy, optimize the environment of the city}

The environment of Lanzhou has been damaged to a great extent although the economy o has a spurt growth, and this is not what we really want. The sustainable development of living environment is the living environment factors, in other words, the environmental resources, especially scarce resources, can be used long-term, sustained by the residents of the city. We must energy saving, reduce the energy consumption by improving the structure of heat preservation and heat insulation, ventilation technology measures, and vigorously promote the use of clean energy such as solar energy, wind energy to instead non renewable energy and easy to cause pollution such as oil and coal. Save water, promotion of water reuse system, rainwater collection in modern architecture and reduce the large lawn project. Economical use of land, build or not to build a large square and Prohibit the construction of large villas and so on. In general is to adhere to the recycling economy, the traditional linear resource consumption growth, change to intensive economy rely on natural resources to the development of ecological cycle. Material recycling process form a "natural resources - products - renewable resources consumption" and ultimately into the less resource, high working efficiency and low pollutant emission model of economic development.

\section{To strengthen the construction of the new regulation, the city population density}

The effective way to promote the sustainable development of human settlements in the city of Lanzhou is to strengthen the regulation of the city uneven distribution of bearing pressure, increase of city construction of infrastructure facilities and living facilities and promote the construction of new city district to attract population flow Actively. We must reduce pressure by improving the distribution of population of the city because of the huge population caused great pressure to the city development and the environment caused great pressure,. We can improve the distribution of population and reduced population density and Improve urban human settlements environment by the help of Lanzhou new development opportunities, accelerate the rational flow of the population and simultaneous optimization of population structure. Scientific planning of different spheres of industrial layout and main function, undertake the transfer of the center city to the suburbs a part of industry, ease city center due to excessive accumulation of industry and population pressures, speed up the center of urban construction and promote the coordinated development of suburban areas, suburbs and rural economic.

\section{Construction of the expansion of the ecological space planning, realize the sustainable development of human settlements space}

The position of the modern city target will lead to population, resources and productivity of high concentration and the city common ecological imbalance. Good city living environment needs to have a larger space for development of ecology, and City human settlements environment sustainable development must be in the more development planning and development regulation of the city space in the ecological system of reasonable and orderly. In all the country, Lanzhou is a big city with a certain scale after years of development, but city land distribution in long $45 \mathrm{~km}$, width $2-8 \mathrm{~km}$ of the basin because the city is located in the valley and limited by the two mountains in north and south. The strip city of narrow for north and south and long for east and west will limited in the development of space between the north and the South, and effect the social and economic development and the city human settlements environmental construction, so we must build the ecological environment and expand the target to sustainable the space layout of living environment. 


\section{Conclusions}

The city is the regional core and the signs of the human modern civilization, it developed with the human civilization and development. Where there Is no living environment that harmony with nature and safe, there is no comfortable life along with our country the quality requirements of the living environment of continuous improvement. Therefore, building a good living environment of the city and establish the ecological City is the inexorable trend of the city and ideal mode of the city development of twenty-first century.

In the construction of development of human living environment of Lanzhou in the future, we need to do three things: First, suit its measures to local conditions to improve city ecological planning and layout. Second, divide the functions of city living environment Scientifically and design the future direction of development and the expansion of city space for the future according to the geological conditions of Lanzhou and the ecological environment carrying capacity of the city area. Third, develop the circular economy vigorously and rely on scientific and technological progress and system innovation to combine with production, circulation, consumption, recycling and ecological environment protection and construction, and then change the mode of economic growth high consumption of the extensive and high emission of Lanzhou, and construct the new model of economic development that combine ecological benefit and economical benefit, construct friendly environment society, promote the economic development and the living environment of harmony and finally to realize the sustainable development of human settlements in Lanzhou.

\section{Acknowledgements}

This work was financially supported by the Foundation of Construction Scientific and Technological Project of Gansu Province ( JK2012-53 ), the Foundation of Scientific and Technological Project of Gansu Province (Youth) (1212RJYA009 ), the Humanities and Social Science Foundation Lanzhou University of Technology (2011-5) and the National Natural Science Foundation Project(51208243).

\section{References}

[1] Zhang Yafen. Analysis on Urban Human Settlements of China with Sustainable Development View [D]. Chengdu University of Technology,2008. (In Chinese).

[2] Li Bin. Study on the Assessment and Optimization of Urban Human Settlements Construction Quality in Lanzhou [D]. Northwest Normal University,2004. (In Chinese ). 